Gut, 1969, 10, 871-881

\title{
Solitary ulcer of the rectum
}

\author{
M. R. MADIGAN AND B. C. MORSON \\ From the Research Department, St Mark's Hospital, London
}

SUMMARY Solitary ulcer of the rectum is usually a disease of young adults of either sex which has a characteristic appearance on sigmoidoscopy. Distinctive changes may also be seen in biopsies taken from mucosa adjacent to the ulcer.

The name 'solitary ulcer' is misleading because more than one ulcer may be present. Moreover, there is a preulcerative phase which is clinically and histologically recognizable.

The condition is essentially benign and may persist for many years unchanged. It has not responded satisfactorily to medical or surgical methods of treatment.

The cause of solitary ulcer is unknown. Different views on the pathogenesis are discussed.

The condition known as 'solitary ulcer' of the rectum is uncommon and there are few references in the literature. The name is misleading because there may be more than one ulcer and there is a stage of the disease when no ulceration is present. According to Haskell and Rovner (1965) the condition was first described by Cruveilhier (1829-42). Allen (1966), Epstein, Ascari, Ablow, Seaman, and Lattes (1966), and Wayte and Helwig (1967) have described what appears to be a similar or related pathology under the title 'Hamartomatous inverted polyps of the rectum' and 'Colitis cystica profunda'. The expression 'solitary ulcer' has been used at St Mark's Hospital since before World War II (Lloyd-Davies, 1969).

The object of this paper is to describe the clinical features, pathology, treatment, and behaviour of 68 patients with solitary ulcer of the rectum seen at St Mark's Hospital between 1931 and 1967. Fortyone of these were contacted and examined by one of us (M.R.M.); 27 others who could not be traced were included because study of their case notes revealed sufficient evidence to satisfy the criteria for diagnosis.

\section{CLINICAL ANALYSIS}

AGE AND SEX The age distribution is given in Table I. The youngest was aged 14 years and the oldest 68 years. The Table shows that solitary ulcer of the rectum is most common among young adults. The condition is equally common among men and women.

SOCIAL AND FAMILY HISTORY No significant correlation could be found with occupation, social class,
TABLE I

AGE AND SEX DISTRIBUTION OF SOLITARY ULCER OF THE RECTUM

\begin{tabular}{llrrrrrr}
\multicolumn{1}{l}{ Age Group $(y r)$} \\
\cline { 2 - 8 } & $10-19$ & $20-29$ & $30-39$ & $40-49$ & $50-59$ & $60-69$ & Total \\
\hline Male & 4 & 15 & 7 & 4 & 3 & - & 33 \\
Female & 5 & 7 & 8 & 9 & 3 & 4 & 35 \\
Total & 9 & 22 & 15 & 13 & 6 & 3 & 68
\end{tabular}

race, foreign travel, or smoking and drinking habits. There was no family history of the condition.

SYMPTOMS These are given in Table II. Several patients presented initially with constipation (four), rectal prolapse (two), difficulty in defaecation (two), sensation of incomplete evacuation (one), and in one symptomless patient the ulceration was discovered on routine examination.

Bleeding was in large amounts in five patients, four of whom required transfusion. In 33 out of the 68 studied it was moderate in amount, meaning the passage of not more than a cupful of blood. In the remainder of those with bleeding the amount passed

TABLE II

SYMPTOMS OF PATIENTS WITH SOLITARY ULCER OF THE RECTUM

\begin{tabular}{lc} 
Symptom & $\begin{array}{l}\text { Occurrence } \\
(\%)\end{array}$ \\
\hline Bleeding on defaecation & 91 \\
Passage of mucus on defaecation & 68 \\
Anal or rectal pain and discomfort & 24 \\
Increased frequency of defaecation & 19 \\
Lower abdominal pain & 16
\end{tabular}


was slight. This may persist intermittently for years.

The average time from the onset of symptoms to seeking advice was $5 \cdot 3$ years, some patients waiting up to 10 years.

BOWEL HABIT This was regular in 38 patients $(56 \%)$ and irregular, meaning occasional episodes of diarrhoea or constipation, in $18(26 \%)$. The other 12 patients relied on laxatives for regular bowel action.

MENTAL STATE It has been stated that patients with solitary ulcer of the rectum are sometimes mentally abnormal. Sixty ( $88 \%$ ) were judged normal. Eight $(12 \%)$ showed various degrees of mental disturbance. This was decided simply by observing behaviour and talking to the patients.

DIGITAL EXAMINATION OF THE RECTUM The results were normal in $24(35 \%)$ patients. Induration was most noticeable in those with the nonulcerative stage, although it is usually slight and there were no cases of fixity of the rectal mucosa to the surrounding structures.

SIGMOIDOSCOPY Forty-eight $(70 \%)$ had a single ulcer and $20(30 \%)$ had more than one ulcer. There were eight patients with two ulcers and three with three ulcers. The other nine had multiple small areas of scattered ulceration (Fig. 1).

The site of the ulcers is given in Table III. It will be seen that they are found with the greatest frequency on the anterior aspect of the rectal wall. They are frequently situated astride a valve of Houston. The distance of the ulcers from the anal margin varied from 3 to $15 \mathrm{~cm}$, but most of them were found at 7 to $10 \mathrm{~cm}$.

TA BLE III

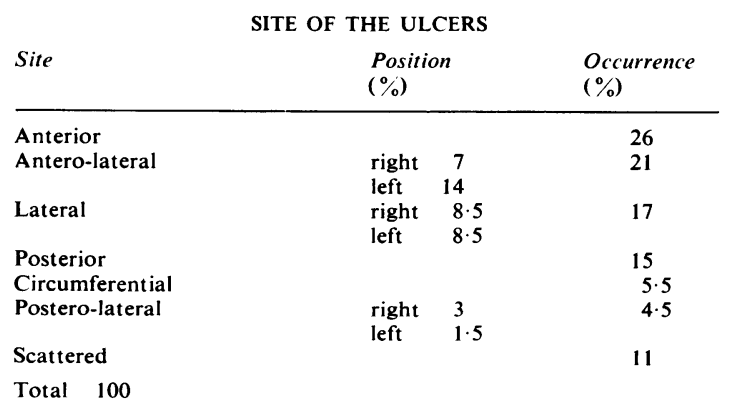

Most of the ulcers were about $2 \mathrm{~cm}$ in diameter but they varied from a tiny spot, the size of a match head, to one large lesion measuring $5 \times 3 \mathrm{~cm}$. In about one third of all patients the ulcer had an irregular outline (Fig. 2). In another third, the ulcer was linear in shape and measured from a few millimetres to $2 \mathrm{~cm}$ across. In most of the remainder the ulcers were round or oval, but in a few there were stellate and serpiginous forms.

The base of a solitary ulcer has a characteristic appearance. It is covered with a white, grey, or yellowish slough like wash leather. The ulceration is shallow, being only slightly depressed below the surrounding intact mucosa. The flat edge is clearly marked by a line of hyperaemia which sharply demarcates the ulcer from adjacent intact mucous membrane (Figs. 3 and 4). However, not all ulcers have this typical appearance. Occasionally the base appears pink and granular through the slough. The surrounding mucous membrane is heaped up, nodular, or lumpy in appearance in about half the patients (Fig. 5), or it may appear velvety, granular, or as punctuate red areas (Fig. 6). These changes extend for a few millimetres to a few centimetres from the ulcer and may be confluent if there is more than one ulcer. The rest of the rectal mucosa is quite normal except that in several patients a granular, appearance up to $17 \mathrm{~cm}$, or greyish spots at the ano-rectal ring like squamous metaplasia, were observed. In about a third of patients the mucosa surrounding the ulcer appeared oedematous, and might bleed slightly when touched with the sigmoidoscope.

\section{INVESTIGATIONS}

Thirty-five of the 68 patients had barium enema radiographs of which 22 were quite normal. Five were reported as having narrowing or irregularity of the restal wall, while the remainder had apparently unrelated conditions of the colon, such as mild diverticular disease.

A few patients had low haemoglobin values, but there were no other abnormal haematological findings.

The Wassermann reaction was carried out on 44 patients and was positive in only one. Gonococcal complement-fixation tests were negative in 14 patients and the Frei test was negative in eight. Examination of faeces revealed no significant abnormalities.

\section{OTHER ANORECTAL DISEASE}

Thirty-three patients $(48 \%)$ had local conditions other than solitary ulcer. There were haemorrhoids in 22 $(33 \%)$ and prolapse of the rectum in eleven $(16 \%)$. Three of these prolapses were complete, one showing the solitary ulcer at its apex. The others were slight, 


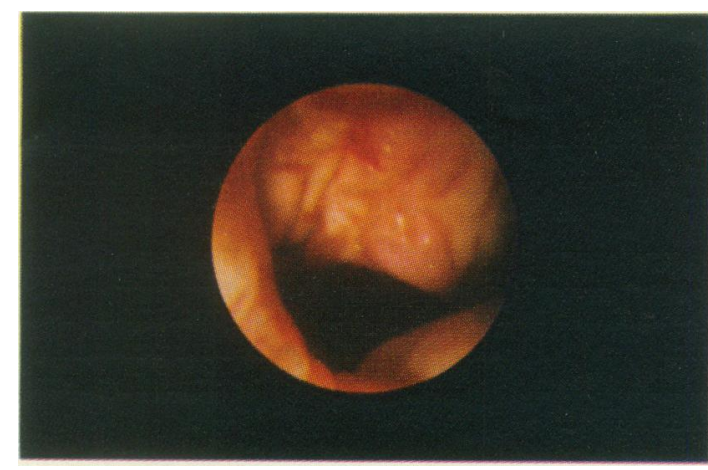

FIG. 1. Multiple small scattered solitary ulcers.

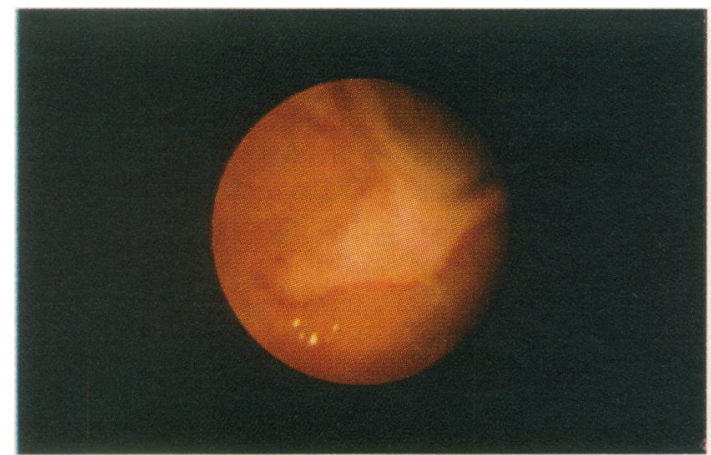

FIG. 3.

FIGS. 3 and 4. The appearance of a typical solitary ulcer.

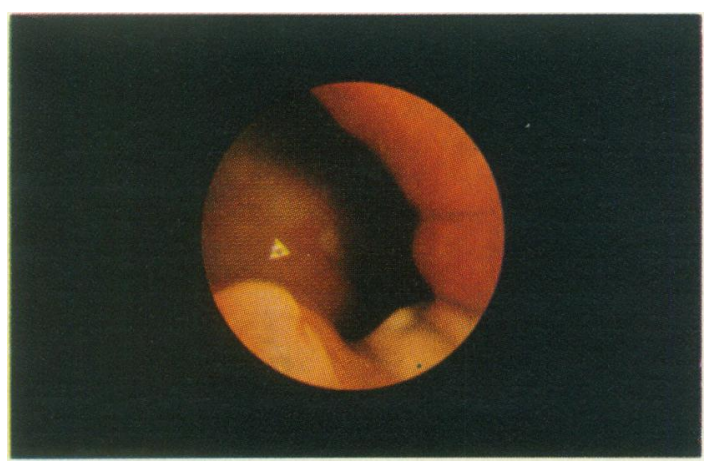

FIG. 5. Nodular, lumpy mucosa surrounding an ulcer.

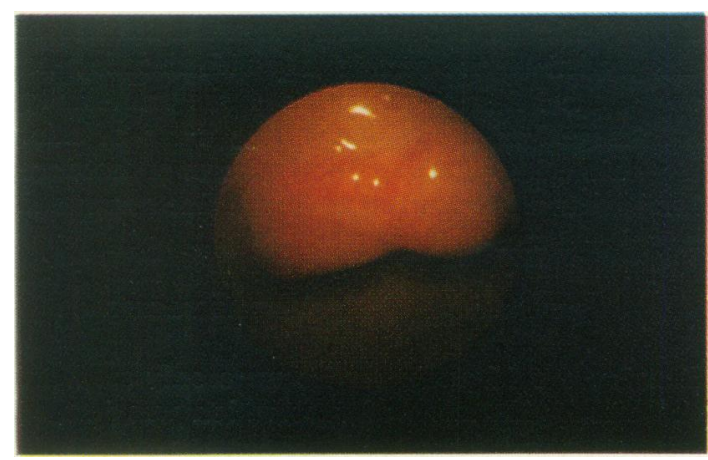

FIG. 7. Lumpy, polypoid, hyperaemic mucosa.

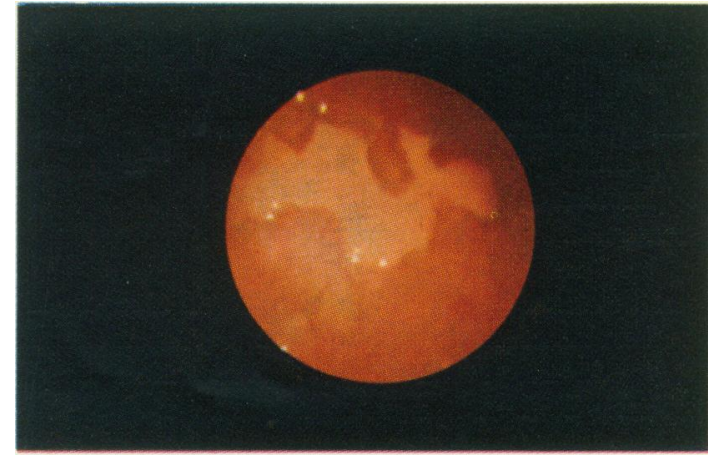

FIG. 2. Irregular ulcer.

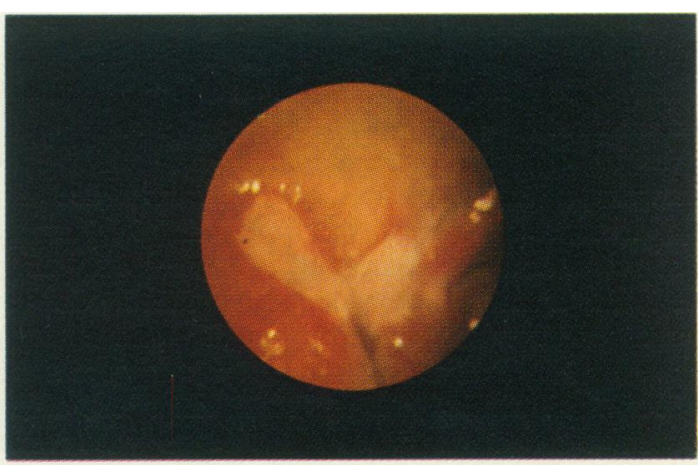

FIG, 4.

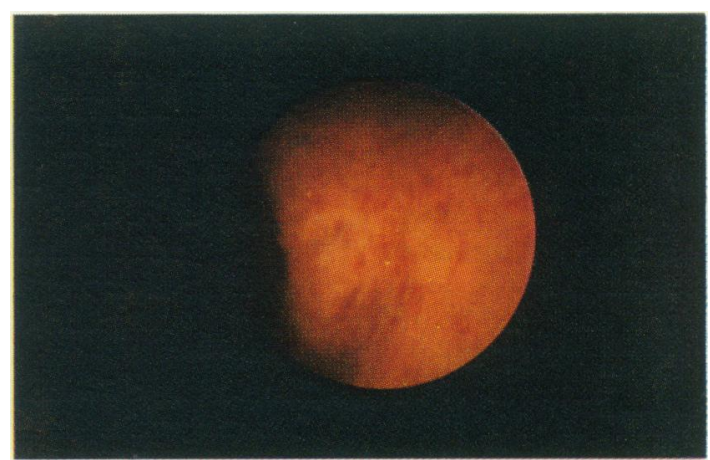

FIG. 6. Punctate red mucosa surrounding an ulcer.

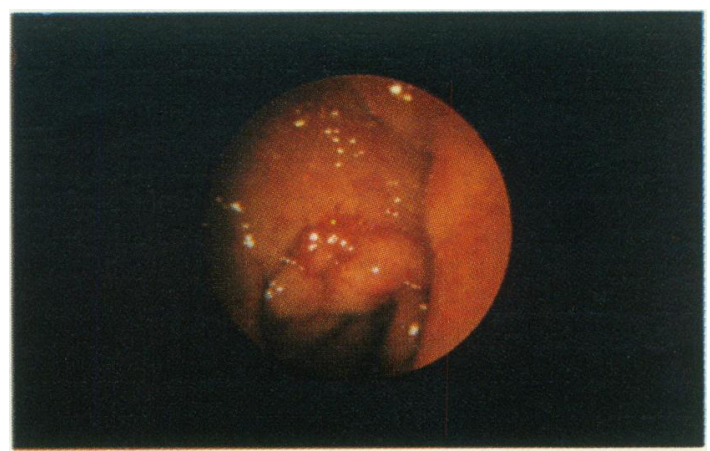

FIG. 8. Puckered scarred-mucosa. 
ranging from a tendency to mucosal pouting only to partial prolapse. Three patients had lax anal sphincters with a bulging perineum. Two patients had operations for correction of the prolapse but the ulcers persisted.

Other associated conditions included leucoplakia and excoriation of the anal skin (seven patients) and fissure-in-ano (seven patients). One patient also had an unrelated carcinoma of the rectum.

\section{TREATMENT}

Many empirical treatments have been tried and there is very little evidence that any of them have been effective. Every known kind of suppository has been tried for periods of several weeks to months in varying doses. The active ingredients have included adrenaline, antihistamines, arsenic,bismuth,decicaine, hydrocortisone and other steroids, ichthammol, mercury, and witch hazel. Likewise, steroid retention enemas and carbenoxalone have failed. Caustics, such as silver nitrate, heavy metals, snake venom, tannic acid, and many proprietary compounds have been used without success. Antibiotics and chemotherapeutic agents have been given parenterally, locally, or by mouth in varying doses, and vitamins have also been tried.

SURGICAL TREATMENT Six patients underwent major procedures. Two had a resection of part of the rectum, including the ulcer, with anastomosis of the remaining rectum to the pelvic colon. In both patients the ulcers recurred: one as an encircling ulcer at the anastomosis which 16 years later narrowed the rectum at this point leaving some residual hyperaemia only; the other had a recurrence seven months postoperatively and the ulcer persisted for two years before resolving spontaneously to leave a scarred area.

Three cases had a proximal colostomy. In one the ulcer healed in six weeks, but recurred after four months and then healed nine months later; then the colostomy was closed. Nine months after that several solitary ulcers were still present. A year later an end-colostomy was made and the pelvic colon resected. A year after this a typical solitary ulcer was present at 8 to $10 \mathrm{~cm}$.

The second patient had rectal prolapse. A transverse colostomy was made, but it did not affect the ulcer. Bleeding was so severe that 10 pints of blood were transfused in a month. Because of this, and the prolapse, the rectum was excised, the only certain method of cure.

The third patient had a rectal prolapse for which she had a local amputation followed by a colostomy and repair of the prolapse from above. As the ulcer did not heal and interference was suspected, the anus was sutured for a time, but bleeding continued. Twelve years later she still had the colostomy and a granulomatous area at the site of the ulcer.

The sixth patient had a solitary ulcer at $4.9 \mathrm{~cm}$ posteriorly and a carcinoma of the rectum at $14 \mathrm{~cm}$ anteriorly. Sixteen days after anterior resection of the rectum the solitary ulcer in the remaining rectum was healed.

MINOR PROCEDURES Several patients had the ulcer cauterized with the diathermy needle, which made the ulcer worse. However, in one patient the ulcer had healed two months after diathermy to its base.

Two patients with rectal prolapse were treated, one by submucous sclerosing injections, after which the ulcer healed but recurred. The second had a Thiersch wire inserted and a granulomatous area treated hy diathermy. Subsequently several solitary ulcers developed.

One patient with anal stenosis and haemorrhoids had the anus dilated and a haemorrhoidectomy. Four years later his solitary ulcer was bigger.

ADMISSION TO HOSPITAL Five patients were admitted for rest, general build-up, examination under anaesthesia, and biopsy of the lesion. One of these required 5 pints of blood in 20 days. In none of them was the ulcer changed in any way.

\section{NON-ULCER STAGE}

There seems to be a stage of this disease which does not show itself as an actual ulcer but which can be recognized as a localized proctitis. Typical ulcers have been observed to heal, only to reappear later. The appearance of the nonulcerated stage is the same as that which is seen around an ulcer. Moreover, the biopsy appearances are similar.

The lumpy, polypoid, hypertrophic, hyperaemic areas of mucosa as described above correspond in size and site to those of solitary ulcers (Fig. 7). The mucosa may appear as a puckered, scarred area (Fig. 8). These areas of mucosal change are, like solitary ulcers, surrounded by normal rectal mucosa, sharply defined and occasionally with an oedematous appearance. Close observation of the granular type of change has shown many tiny areas of microulceration. The intense redness of some of those areas has the same appearance as the red line surrounding a typical ulcer.

\section{DURATION AND FATE OF THE ULCERS}

Leaving out 16 patients who were only seen once, the average duration of observation was just over 


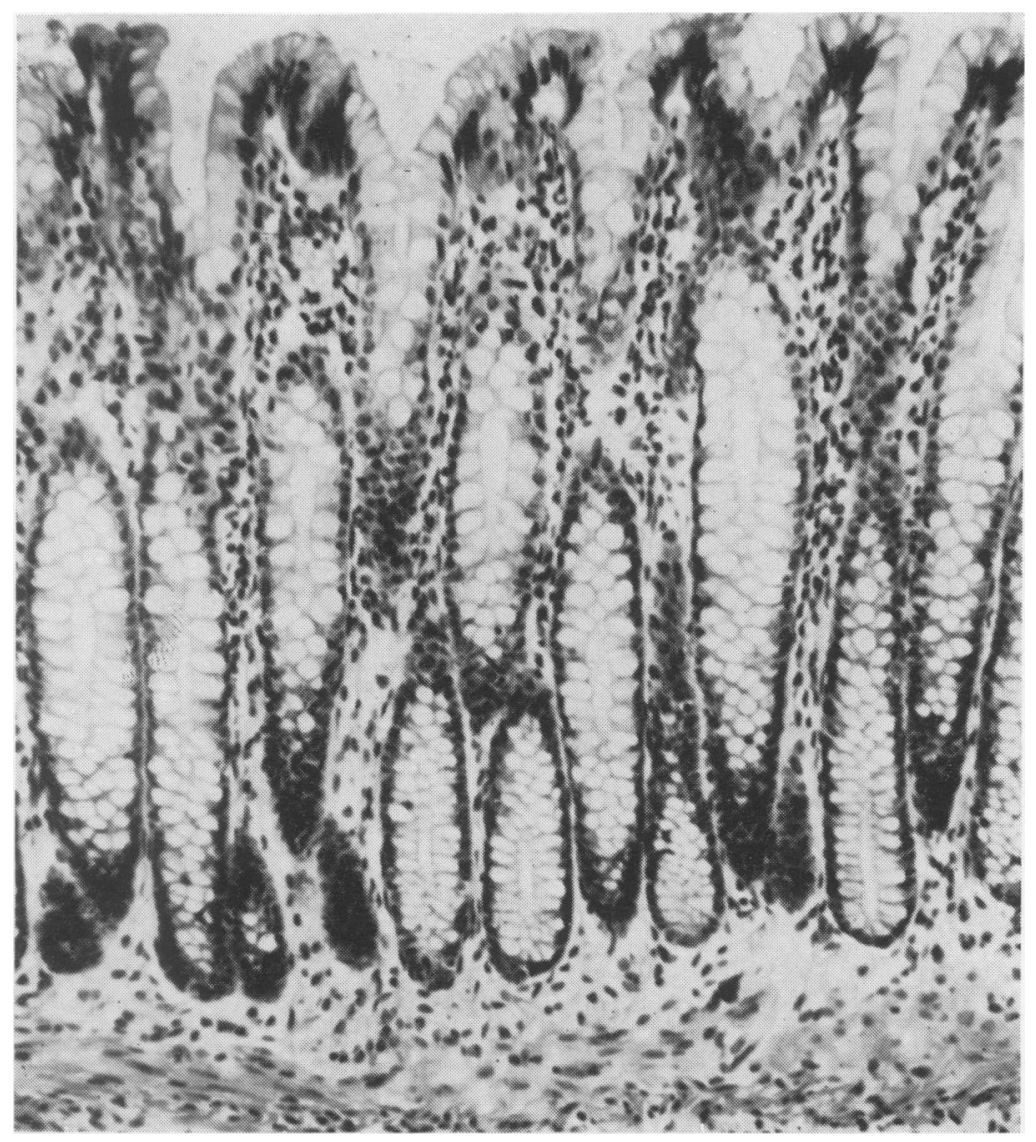

FIG. 9. Normal

rectal mucosa.

eight years. Ulcers change their appearance remarkably little over many years.

The first recorded case in this series is a male patient with a typical description of a solitary ulcer of the rectum, who today, 34 years later, has an exactly similar ulcer in the same situation.

\section{BIOPSY DIAGNOSIS}

A rectal biopsy was performed in $51(75 \%)$ of the 68 patients. Twenty-one of these made no contribution to the clinical diagnosis of solitary ulcer. The probable reason is that biopsy is not easy under outpatient conditions. The ulcer is flat and not readily grasped with the biopsy forceps and bleeding occurs if too large a bite is taken.

In 30 patients the rectal biopsy showed histological appearances suggestive of solitary ulcer. The most characteristic feature is obliteration of the lamina propria of the mucous membrane in the region of the ulcer by fibroblasts and muscle fibres derived from the muscularis mucosae. The fibroblasts lay down collagen which is intimately mixed with the muscle fibres and together they stream towards the mucosal surface between the epithelial tubules (Fig. 10). The muscularis mucosae is often thicker than normal and its fibres are splayed and in continuity with those in the lamina propria. The latter shows no significant increase in the numbers of inflammatory cells.

The epithelial component of the mucous membrane showing the above changes in its lamina propria sometimes shows considerable reactive hyperplasia. There is also a tendency towards goblet cell depletion rather than an excess of mucus production. The tubules sometimes show cystic dilatation. In other cases there is erosion of the superficial mucosa which is covered by mucus, pus, and detached epithelial cells (Fig. 11). The submucosal layer contains an increase in the amount of collagen in the neighbourhood of areas of fullthickness mucosal loss, but is otherwise normal. 


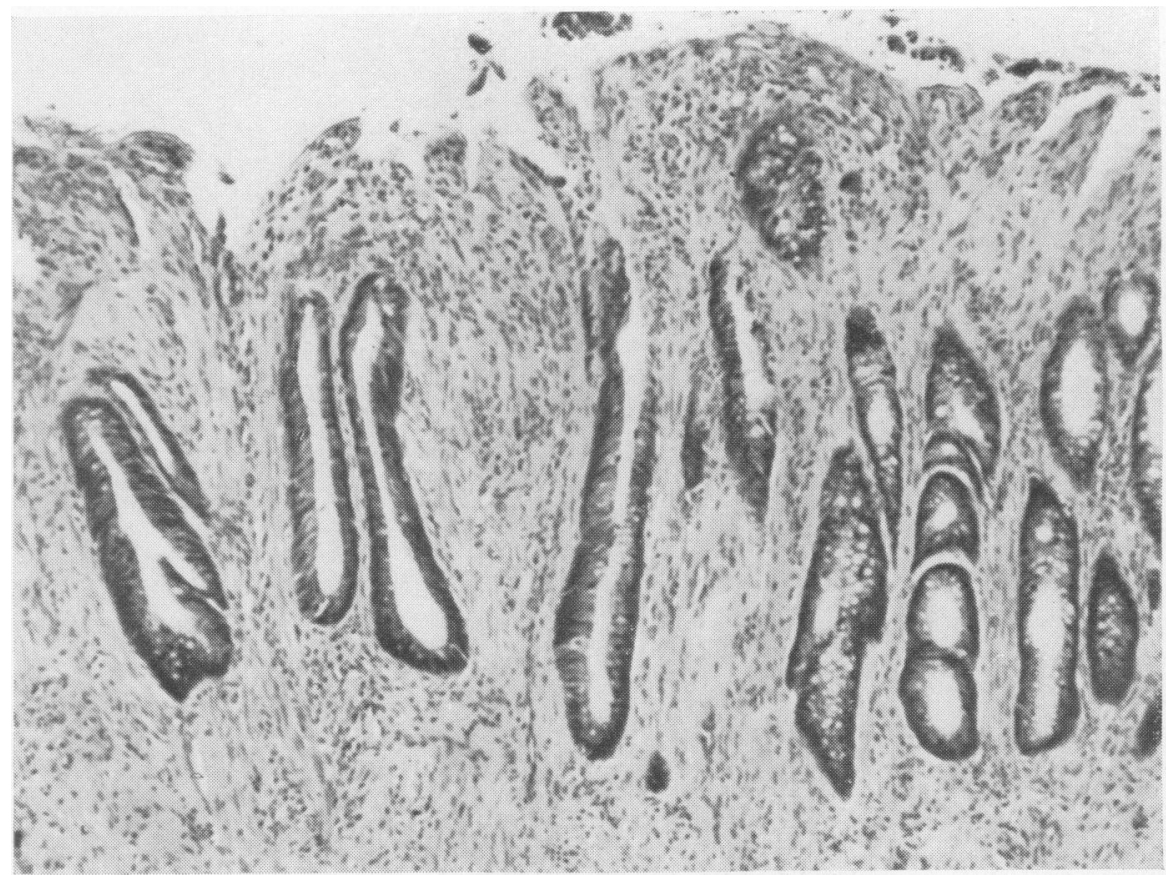

FIG. 10. Biopsy of solitary ulcer.

Epithelial tubules are separated from one another and show reactive hyperplasia with mucin depletion. The lamina propria is obliterated by

smooth muscle and collagen fibres streaming towards the mucosal surface from the muscularis mucosae. There is also superficial erosion of the mucous membrane. Haematoxylin and eosin $\times 100$.

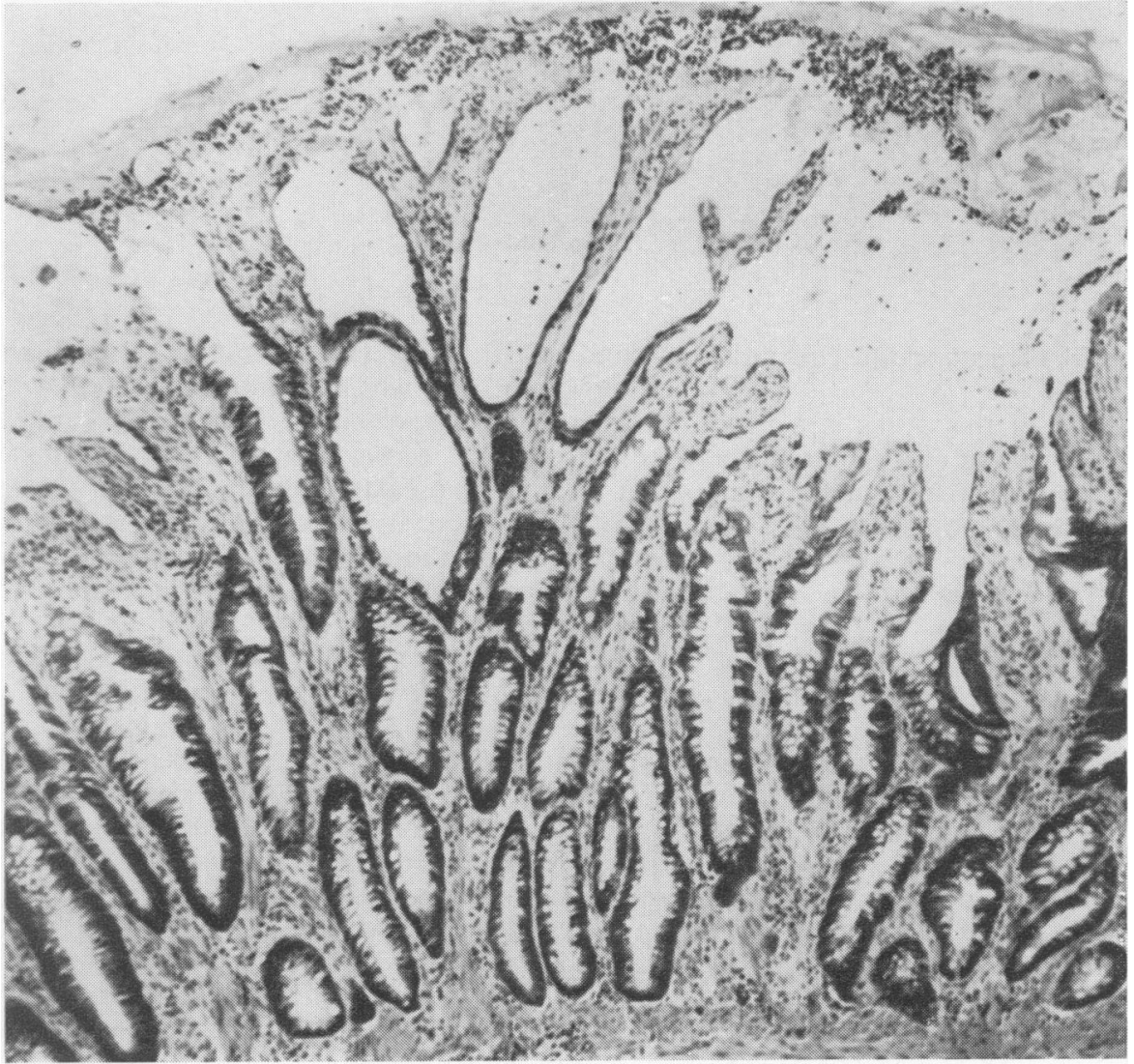

FIG. 11. Biopsy of solitary ulcer. The normal lamina propria is replaced by fibro-muscular tissue streaming towards the surface of the mucosa which shows superficial ulceration and cystic dilatation on the tubules. $\times 100$. 


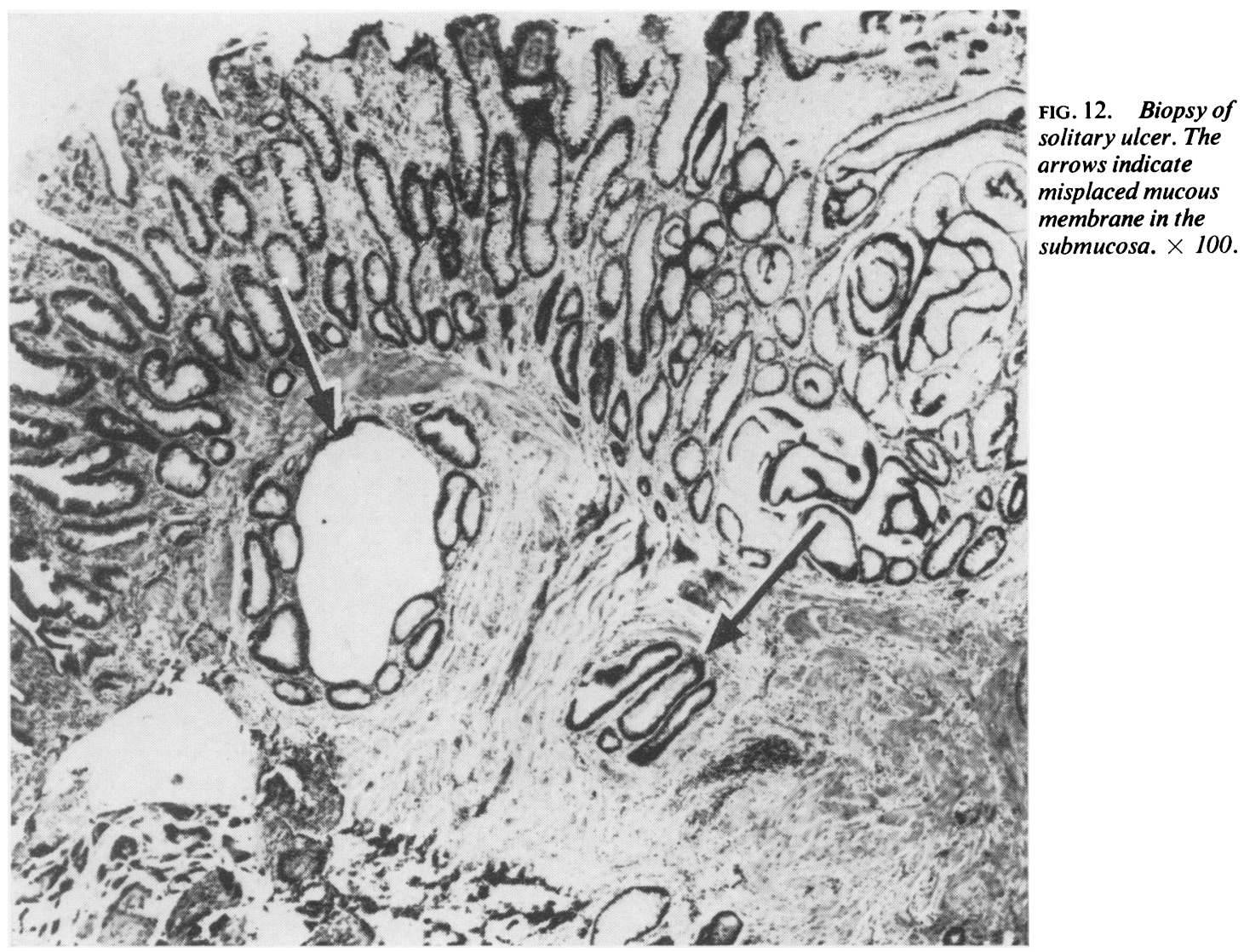

Most biopsies are taken from mucous membrane close to the area of ulceration, but occasionally the ulcer or its edge may be biopsied. This will reveal a zone of necrotic cells covering vascular granulation tissue. Beneath this there is dense fibrosis of the submucosal tissues which probably accounts for the characteristically white appearance on sigmoidoscopy. If the edge of the ulcer is biopsied, regenerating epithelium from the adjacent mucosa will be seen attempting to grow over the ulcerated surface. In five of the 51 biopsies misplaced mucosa, including epithelial elements and lamina propria, were seen in the submucosa (Fig. 12). This misplaced tissue is prone to undergo cystic dilatation due to retention of mucus giving appearances which may be confused with adenocarcinoma. Indeed, we have knowledge of one young patient with solitary ulcer of the rectum who was treated by abdominoperineal excision because the biopsy appearances were falsely reported as malignant. The fibro-muscular obliteration of the lamina propria mentioned above cannot be regarded as specific for the diagnosis of 'solitary ulcer' as a similar appearance is regularly seen in prolapse of the rectum. However, we have not yet seen it under any other circumstances. This histological appearance can thus be described as highly suggestive of solitary ulcer if prolapse of the rectal mucosa has been excluded. When both conditions are present in the same patient it can only be presumed that the histology is in some way a reflection of a common feature in the pathogenesis of two separate disorders.

\section{PATHOLOGY OF SURGICAL SPECIMENS}

Two patients in this series were treated by excision of the rectum. Examination of the surgical specimens revealed changes of considerable interest.

SPECIMEN 1 The patient was a man aged 28 years. The specimen consists of the sigmoid colon and upper rectum (Fig. 13). In the upper rectum there is a flat ulcer involving 


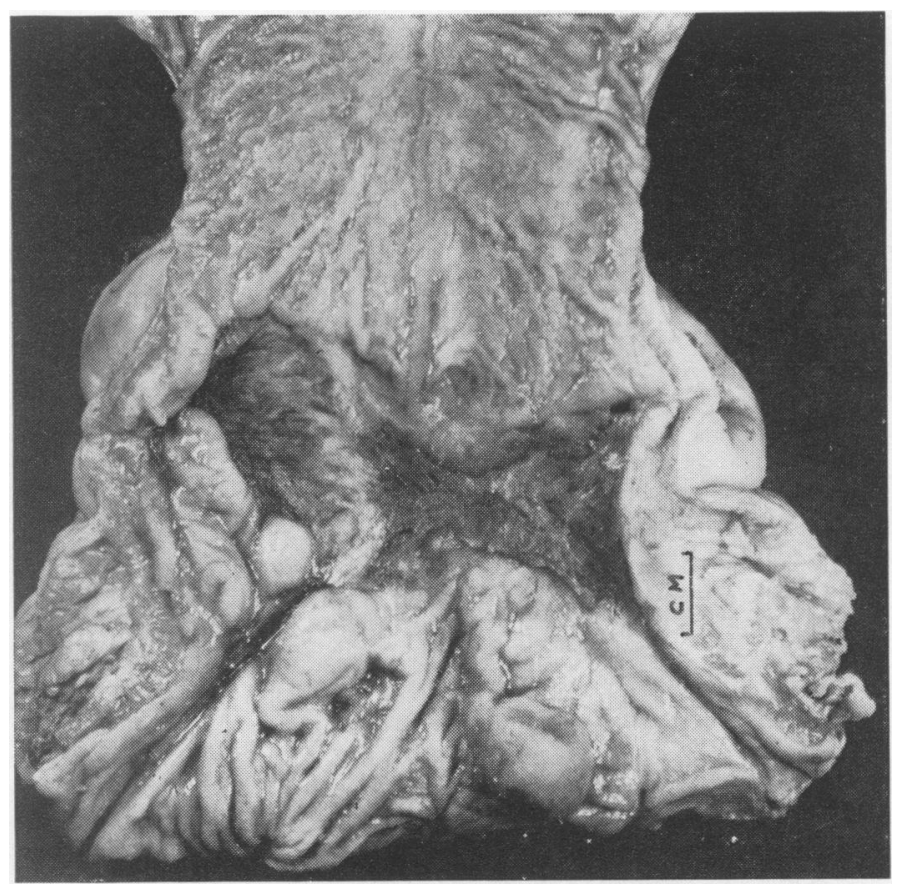

FIG. 13. There is a flat ulcer involving the entire circumference of the upper rectum. The mucous membrane below the ulcer has a nodular appearance due to the presence of submucous cysts.

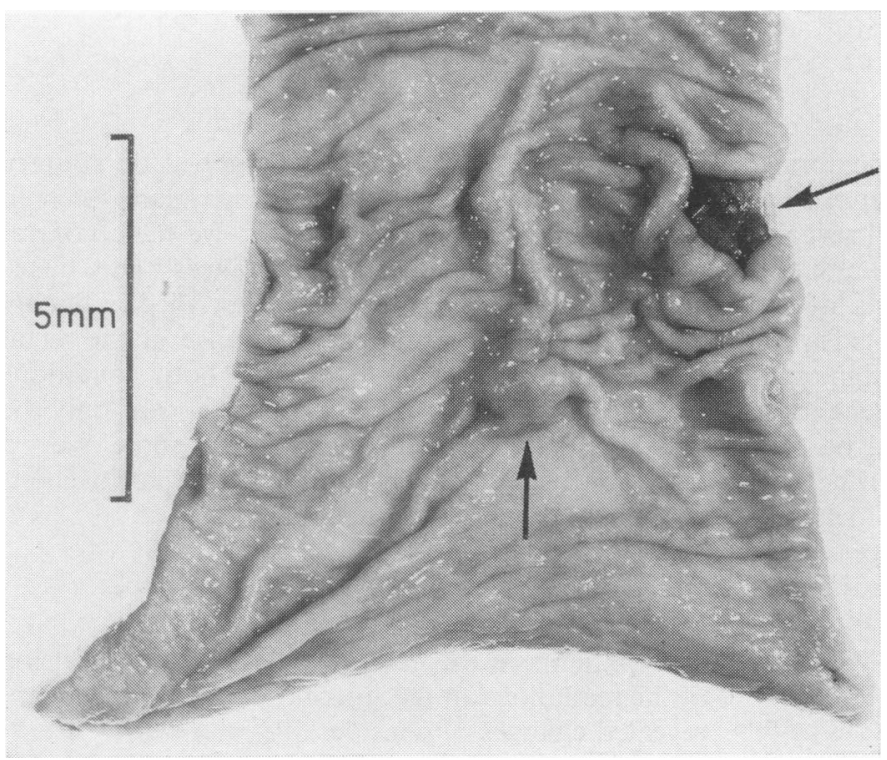

FIG. 14. A clearly defined ulcer (arrowed) is present on the anterior wall of the upper rectum, $7 \mathrm{~cm}$ from the distal limit of excision. On the posterior quadrant of the rectum, $3 \mathrm{~cm}$ from the distal limit, there is a nodule, the cut surface of which shows a mucous cyst in the submucosa (see Fig. 16). 


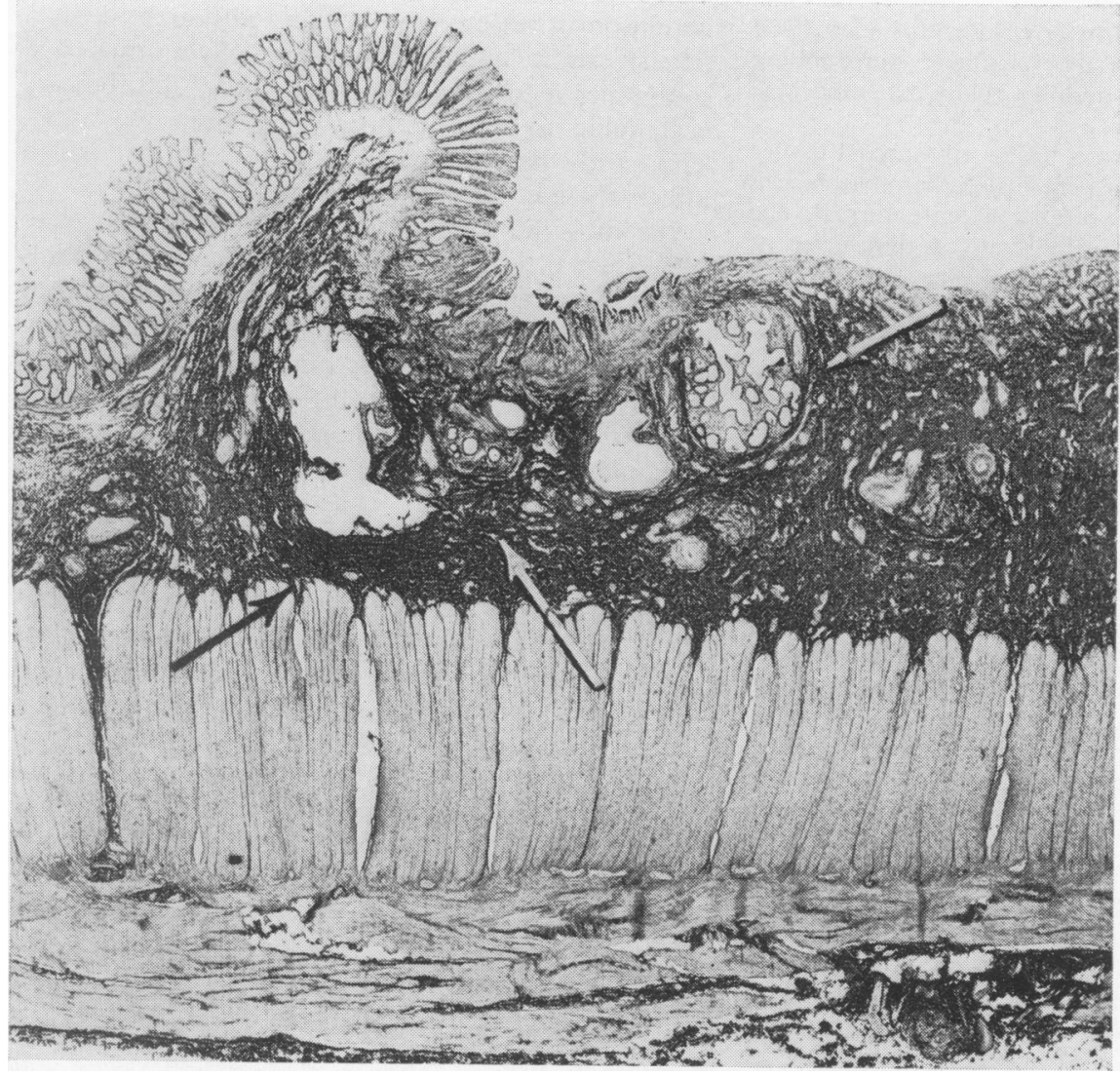

FIG. 15. Section of solitary ulcer. There is formation of dense collagen in the submucosa, but the other layers of the bowel wall are not affected. There is misplaced mucous membrane (arrowed) at the margin of the ulcer. Haematoxylin and eosin $\times 6$.

FIG. 16. Mucus cyst in the submucosa of the rectum. Haematoxylin and eosin $\times 6$. 
the entire circumference of the bowel wall for a length of $3.5 \mathrm{~cm}$. The mucous membrane immediately surrounding the ulcer is flat above and nodular below, but otherwise this appears normal.

Sections show heavy fibrosis in the submucosal tissues at the site of the ulcer, but very little inflammatory cell infiltration. The muscularis propria is quite normal. The surface of the ulcer is covered with a thin layer of granulation tissue. The nodular appearance of the mucous membrane immediately below the ulcer is due to the presence of misplaced mucosa in the submucosa at the edge of the ulcer. This has undergone cystic change. The mucous membrane of the margins of the ulcer shows the histological changes described in the section on 'Biopsy diagnosis'.

SPECIMEN 2 The patient was a woman aged 42 years. The specimen consists of the sigmoid colon and upper rectum (Fig. 14). There is a clearly defined, shallow ulcer $1 \mathrm{~cm}$ in diameter on the anterior wall of the upper rectum about $7 \mathrm{~cm}$ from the distal limit of excision. It is surrounded by normal mucous membrane. On the posterior quadrant of the rectum, $3 \mathrm{~cm}$ from the distal limit of excision and about $2 \mathrm{~cm}$ from the ulcer, there is a nodule, about $1 \mathrm{~cm}$ in diameter, the cut surface of which shows a mucous cyst in the submucosa covered by normal mucous membrane.

Histological sections of the ulcer show heavy submucosal fibrosis covered by a layer of granulation tissue. The muscularis propria is normal. Misplaced mucous membrane is seen at the margins of the ulcer (Fig. 15). The nodule mentioned above, which is quite separate from the ulcer, is a submucosal cyst lined by columnar epithelium and appears to be misplaced rectal mucosa (Fig. 16). The mucous membrane of the margins of the ulcer shows the histological changes described in the section on 'Biopsy diagnosis'.

These two specimens contain what appears to be the same pathology. The mucosal changes at the margins of the ulcers show identical appearances as those described for the biopsy diagnosis. Both specimens contain misplaced mucous membrane in the submucosa at the edge of the ulcer, and one has it at a distance from the main lesion as well.

\section{DISCUSSION}

The recognition of solitary ulcer of the rectum is relatively easy because of the striking sigmoidoscopic appearance. Indeed, half of the cases reported here were diagnosed solely on the clinical history and appearance of the lesion. In the other half the diagnosis was supported by the biopsy appearances. The nonulcerative phase is also recognizable, but has to be distinguished from other forms of proctitis. Biopsy is useful for this purpose.

The only serious complication of solitary ulcer is massive haemorrhage and this is rare. Otherwise the condition is essentially benign, although it may persist for a great many years. Symptoms will sometimes regress spontaneously, but if not they are acceptable to patients who have been reassured. This study has not revealed any treatment which affects the course of the disease.

It is most important to distinguish the appearances of solitary ulcer from cancer of the rectum, Crohn's disease, proctocolitis, and specific granulomatous conditions, such as lymphogranuloma venereum. Laboratory tests, especially biopsy, are helpful.

This study has revealed little helpful information about the aetiology or pathogenesis of solitary ulcer, although the following factors have been given special consideration.

Self-inflicted trauma is a possible cause because $20 \%$ of patients admitted rectal digitation. But it is not easy to self-digitate very far up the rectum and the sharply demarcated appearance of the ulcer, its variable position, tendency to be multiple, and stationary behaviour do not support the traumatic theory of origin. In rectal clinics many patients will admit to aiding defaecation with the finger, spoon, or other instrument, yet solitary ulcer is a rare condition. Cutting of the finger nails and close observation in hospital have failed to prove that trauma is the principal cause in any of our patients.

Sixteen patients also had rectal prolapse. The relationship between these two conditions is not obvious, but the fibromuscular obliteration of the lamina propria of the rectal mucosa common to both conditions may be significant. One suggestion is that excessive straining at stool may lead to internal mucosal prolapse with repeated trauma of the prolapsed mucous membrane by a contracting hypertonic anal sphincter. But most patients with solitary ulcer have no evidence of internal prolapse.

Wayte and Helwig (1967) have described the pathology of patients with localized submucosal cysts of the rectum under the title 'Colitis cystica profunda' and refer to the clinical resemblance between their cases and those described by Haskell and Rovner (1965) as 'solitary ulcer'. Wayte and Helwig (1967) and Epstein et al (1966) believe that the submucosal cysts are probably the result of an inflammatory process.

Allen (1966) used the title 'Hamartomatous inverted polyps of the rectum' to describe what appears to be the same condition as 'solitary ulcer' and localized 'colitis cystica profunda'. Our studies give rather more support to the hamartomatous rather than the inflammatory theory of origin, although the use of the word 'hamartoma' is questioned. The long history, failure to respond to anti-inflammatory treatment, occurrence in young adults, and absence of any evidence of an acquired 
process seem to point in this general direction. Wayte and Helwig (1967) speculate whether such chronic ulcers could be precursors of localized submucosal cysts, but it is just as likely, in our opinion, that the reverse is true. 'Solitary ulcer' may be primarily a localized heterotopia or congenital duplication of the rectal mucosa which undergoes cystic change due to retention of secreted mucin. If such cysts burst into the lumen there will be secondary inflammation with ulceration. The non-ulcerative phase observed clinically, together with the boggy, lumpy texture of the mucosa in the neighbourhood of ulcers, could really be a manifestation of a preulcerative state.

We wish to thank the consultant staff of St Mark's Hospital, particularly Mr O. V. Lloyd-Davies, FRCS, for helpful advice and permission to study their patients.
The photographs were taken by $\mathrm{Mr}$ Norman Mackie. We should also like to thank $\mathrm{Mr}$ Lloyd Soodeen for technical help and Miss Margaret McIntosh for secretarial assistance. The expenses of this investigation were provided by the Research Endowment Funds of St Mark's Hospital.

\section{REFERENCES}

Allen, M. S., Jr. (1966). Hamartomatous inverted polyps of the rectum. Cancer, 19, 257-265.

Cruveilhier J. (1829-42). Ulcère chronique du rectum. In Anatomie Pathologique du Corps Humain vol. 2, livr. 25, maladies du rectum, p. 4. J. B. Baillière, Paris.

Epstein, S. E., Ascari, W. Q., Ablow, R. C., Seaman, W. B., and Lattes, R. (1966). Colitis cystica profunda. Amer. J. clin. Path., 45, 186-201.

Haskell, B., and Rovner, H. (1965). Solitary ulcer of the rectum. Dis. Colon Rect., 8, 333-336.

Lloyd-Davies, O. V. (1969). Personal communication

Wayte, D. M., and Helwig, E. B. (1967). Colitis cystica profunda. Amer. J. clin. Path., 48, 159-169. 